\title{
Primary Cesarean Birth
}

National Cancer Institute

\section{Source}

National Cancer Institute. Primary Cesarean Birth. NCI Thesaurus. Code C114139.

The first surgical delivery of one or more intrauterine fetuses though an abdominal incision in a woman without prior cesarean delivery. 